Article

\title{
Chitosan/Alginate Nanoparticles for the Enhanced Oral Antithrombotic Activity of Clam Heparinoid from the Clam Coelomactra antiquata
}

\author{
Guan-Lan Chen ${ }^{1,2}$, Hong-Ying Cai ${ }^{1,2}$, Jian-Ping Chen ${ }^{1,2}$, Rui Li ${ }^{1,2} \mathbb{D}$, Sai-Yi Zhong ${ }^{1,2,3,4, *}$, Xue-Jing Jia ${ }^{1,2}$, \\ Xiao-Fei Liu ${ }^{1,2}$ and Bing-Bing Song ${ }^{1,2}$
}

1 Guangdong Provincial Key Laboratory of Aquatic Product Processing and Safety, Guangdong Province Engineering Laboratory for Marine Biological Products, Guangdong Provincial Engineering Technology Research Center of Seafood, Guangdong Provincial Science and Technology Innovation Center for Subtropical Fruit and Vegetable Processing, College of Food Science and Technology, Guangdong Ocean University, Zhanjiang 524088, China; cgl202112@163.com (G.-L.C.); 13414866246@163.com (H.-Y.C.); cjp516555989@gdou.edu.cn (J.-P.C.); liruihn@163.com (R.L.); jiaxj@gdou.edu.cn (X.-J.J.); liuxf169@126.com (X.-F.L.); 15891793858@163.com (B.-B.S.)

2 Guangdong Province Key Laboratory of Aquatic Products Processing and Safety, Guangdong Province Engineering Laboratory for Marine Biological Products, School of Food Science and Technology, Guangdong Ocean University, Zhanjiang 524088, China

3 Shenzhen Institute, Guangdong Ocean University, Shenzhen 518108, China

4 Collaborative Innovation Center of Seafood Deep Processing, Dalian Polytechnic University, Dalian 116034, China

* Correspondence: zhongsy@gdou.edu.cn; Tel.: +86-188-2669-9336

check for updates

Citation: Chen, G.-L.; Cai, H.-Y.; Chen, J.-P.; Li, R.; Zhong, S.-Y.; Jia, X.-J.; Liu, X.-F.; Song, B.-B. Chitosan/Alginate Nanoparticles for the Enhanced Oral Antithrombotic Activity of Clam Heparinoid from the Clam Coelomactra antiquata. Mar. Drugs 2022, 20, 136. https://doi.org/ $10.3390 / \mathrm{md} 20020136$

Academic Editors: Hitoshi Sashiwa, Maila Castellano and Andrea Dodero

Received: 14 January 2022

Accepted: 10 February 2022

Published: 12 February 2022

Publisher's Note: MDPI stays neutral with regard to jurisdictional claims in published maps and institutional affiliations.

Copyright: (c) 2022 by the authors. Licensee MDPI, Basel, Switzerland. This article is an open access article distributed under the terms and conditions of the Creative Commons Attribution (CC BY) license (https:// creativecommons.org/licenses/by/ $4.0 /)$.

\begin{abstract}
Chitosan/alginate nanoparticles (DG1-NPs and DG1/Cur-NPs) aiming to enhance the oral antithrombotic activity of clam heparinoid DG1 were prepared by ionotropic pre-gelation. The influence of parameters, such as the concentration of sodium alginate (SA), chitosan (CTS), $\mathrm{CaCl}_{2}$, clam heparinoid DG1, and curcumin (Cur), on the characteristics of the nanoparticles, were investigated. Results indicate that chitosan and alginate can be used as polymer matrices to encapsulate DG1, and nanoparticle characteristics depend on the preparation parameters. Nano-particles should be prepared using $0.6 \mathrm{mg} / \mathrm{mL}$ SA, $0.33 \mathrm{mg} / \mathrm{mL} \mathrm{CaCl}_{2}, 0.6 \mathrm{mg} / \mathrm{mL} \mathrm{CTS}, 7.2 \mathrm{mg} / \mathrm{mL}$ DG1, and $0.24 \mathrm{mg} / \mathrm{mL}$ Cur under vigorous stirring to produce DG1-NPS and DG1/Cur-NPS with small size, high encapsulation efficiency, high loading capacity, and negative zeta potential from approximately -20 to $30 \mathrm{mV}$. Data from scanning electron microscopy, Fourier-transform infrared spectrometry, and differential scanning calorimetry analyses showed no chemical reaction between DG1, Cur, and the polymers; only physical mixing. Moreover, the drug was loaded in the amorphous phase within the nanoparticle matrix. In the acute pulmonary embolism murine model, DG1-NPs enhanced the oral antithrombotic activity of DG1, but DG1/Cur-NPs did not exhibit higher antithrombotic activity than DG1-NPs. Therefore, the chitosan/alginate nanoparticles enhanced the oral antithrombotic activity of DG1, but curcumin did not further enhance this effect.
\end{abstract}

Keywords: clam heparinoid; oral administration; antithrombotic; chitosan/alginate nanoparticles

\section{Introduction}

Venous thromboembolism (VTE), including deep vein thrombosis and pulmonary thromboembolism, represents the third leading vascular disease after acute myocardial infarction and stroke [1,2]. Heparin (HP) is a widely used anticoagulant owing to its excellent effects for preventing and treating VTE [3]. HP is administered by the parenteral route, which is inconvenient and leads to lower patient compliance compared to other routes. However, degradation by gastric acid, heparanase in the liver, and poor absorption and utilisation by the intestinal epithelium and lymph caused by the considerable molecular weight and negative charge of HP lead to a low oral absorption [4]. Although oral 
anticoagulants such as vitamin $\mathrm{K}$, dabigatran, rivaroxaban, apixaban, and edoxaban are available on the market, HP is still the most effective anticoagulant [5]. Therefore, highly orally active oral formulations of HP are urgently needed to be developed.

Heparinoid, also known as "mucopolysaccharide polysulfated," refers to heparin, acetyl heparan sulfate (HS), heparin-like molecules of plant and animal origin, and sulfated polysaccharides, among other sulfated polysaccharides that have similar structure and properties to heparin [6]. The current production of commercial heparins suffers from insufficient resources, biological contamination, and susceptibility to bleeding side effects. The development of marine origin heparinoids is one of the strategies to remedy these problems [7]. The heparinoid G15 from the clam Coelomactra antiquata is a homogeneous glycosaminoglycan with a potent anticoagulant and fibrinolytic activity, and it is mainly composed of $\rightarrow 4$ )- $\alpha$-IdoA2S-( $1 \rightarrow 4$ )- $\alpha$-GlcNS3S6S (or GlcNS6S)-( $1 \rightarrow 4)-\beta$-GlcA- $(1 \rightarrow 4)-\alpha-$ GlcNS6S (or GlcNAC)-(1 $\rightarrow$ [8]. G2 is prepared by using the extraction of G15 as a reference, and DG1 is a low molecular weight fragment of the vitamin-catalysed free-radical depolymerisation of G2. In a previous study, in a mice blacktail model, we found that gavage of equal doses of DG1, G2, and heparin sodium had a comparable ability to reduce the blacktail ratio in mice [9].

Curcumin (Cur) used as a spice, food coloring, and traditional herbal medicine, is a natural polyphenolic component of Curcuma longa, has been widely used in complementary and alternative medicine because it is non-toxic, safe, and has antioxidant, lipid-regulating, anti-platelet aggregation, antithrombotic, etc. properties [10-12]. Considering the low availability of heparin from clam Coelomactra antiquate [8], in this study, curcumin and clam heparinoid DG1 were used as oral antithrombotic agents to develop oral formulations with high oral antithrombotic activity to provide a reference for the application of heparinoids of marine animal origin.

Polymer- and lipid-based nanocarriers, such as polymeric micelles, polymeric nanoparticles, lipid nanocapsules, microemulsions, and solid lipid nanoparticles, have been investigated to improve the HP oral absorption [13-17]. Chitosan and alginate biopolymers have received significant attention in this context because of their non-toxic, biocompatible, and biodegradable properties $[18,19]$. Sodium alginate (SA) is a pH-sensitive material with protonation and dissolution properties under acidic and alkaline conditions, respectively, which prevents drug degradation by gastric acid and provides a targeted release in the intestinal tract. Chitosan (CTS), which is deacetylated from chitin, can enhance the permeation effect and control the release of drugs in the intestinal tract [20,21]. Yin et al. reported the production of sodium alginate/chitosan composite nanoparticles loaded with chondroitin sulfate, in which most CS passed through the stomach and was released in the intestinal tract [22]. The study by Pitchaya et al. confirmed that hydroxyethyl chitosan inhibited the burst release of paracetamol from hydroxyethyl chitosan/SA hydrogels in simulated intestinal fluid [23]. According to Li et al., chitosan-alginate nanoparticles presented a pH-responsive release of nifedipine [24]. Similar results were obtained by Thai et al. [25]. Yan et al. reported that oral fucosylated chondroitin sulfate (FCS) oligomer-gastro resistant microcapsules prepared using a chitosan-coated alginate system presented more robust anticoagulant and antithrombotic effects and weaker bleeding side effects than FCS oligomers [26]. Apart from that, sodium alginate/chitosan nanoparticles have been used to deliver heparin [13] and Cur [27] to improve their bioavailability.

This study used clam heparinoid DG1 and Cur as an oral antithrombotic agent. To further improve the efficacy of DG1, chitosan/alginate nanoparticles DG1-NPs were prepared by ionotropic pre-gelation. Cur was encapsulated in DG1/Cur-NPS nanoparticles to investigate whether Cur and DG1 have synergistic antithrombotic effects. Furthermore, the effects of the concentration of components on the size, zeta potential, encapsulation efficiency, and loading capacity of DG1-NPS and DG1/Cur-NPS were systematically investigated. Fourier-transform infrared spectrometry (FTIR) and differential scanning calorimetry (DSC) were used to analyze the interaction and compatibility of DG1, Cur, and other components. Scanning electron microscopy (SEM) was used to observe the surface morphology of the 
nanoparticles. The effectiveness of the nanoparticles was evaluated in vivo by establishing an acute pulmonary embolism model of mice.

\section{Results}

\subsection{Physicochemical Properties of DG1}

As shown in Table 1, sulfate radicals and uronic acid contents in DG1 were $24.74 \%$ and $22.38 \%$, respectively. The particle size and zeta potential of DG1 were $183.9 \mathrm{~nm}$ and $-25.1 \mathrm{mV}$. Owing to its high sulfate radicals and uronic acid contents, $\mathrm{HP}$ is the biomolecule with the highest negative charge density [28]. Therefore, DG1 is a watersoluble anionic polymer with a high content of uronic acid and sulfate radicals. The maximum initial degradation temperature of DG1 was $246^{\circ} \mathrm{C}$, which indicated that DG1 could withstand the general heating process of the nanoparticle preparation process.

Table 1. Physicochemical properties of DG1.

\begin{tabular}{|c|c|c|c|c|c|}
\hline Name of Sample & $\begin{array}{l}\text { Content of Sulfate } \\
\text { Radical (\%) }\end{array}$ & $\begin{array}{c}\text { Content of Uronic } \\
\text { Acid (\%) }\end{array}$ & $\begin{array}{c}\text { Zeta } \\
\text { Potential (mV) }\end{array}$ & Particle Size (nm) & $\begin{array}{c}\text { Maximum Initial } \\
\text { Degradation } \\
\text { Temperature }\left({ }^{\circ} \mathrm{C}\right)\end{array}$ \\
\hline DG1 & $24.74 \pm 0.64$ & $22.38 \pm 0.93$ & $-25.1 \pm 1.0$ & $183.9 \pm 6.2$ & 246 \\
\hline
\end{tabular}

\subsection{Optimisation of Clam Heparinoid Nanoparticles}

\subsubsection{Effect of SA Concentration on NPs}

In this study, the effect of SA concentration on the size and potential of the nanoparticles was investigated, considering a fixed mass concentration ratio of sodium alginate to calcium chloride to chitosan of 1:0.22:0.15.

As shown in Table 2, the particle size and polydispersity index (PDI) of NPs gradually increased with SA concentration. In comparison, there was no change in the zeta potential of NPs, which was attributed to a fixed mass concentration ratio. In particular, higher SA concentrations improve their chance of interaction with CTS and Ca2 ${ }^{+}$. The zeta potential of NPs is related to the difference between the negative charge carried by SA and the positive charge of calcium chloride and chitosan. The size, PDI, and absolute zeta potential of ideal nanoparticles with high absorption rate and stable condition should be $<1000 \mathrm{~nm},<1$, and -20-30 $\mathrm{mV}$, respectively [29]. SA concentration at $0.6 \mathrm{mg} / \mathrm{mL}$ was considered optimal because it yielded an appropriate zeta potential range $(-26.4 \pm 1.1 \mathrm{mV})$ nanoparticles with a smaller particles size $(236.5 \pm 6.6 \mathrm{~nm})$ (Table 2$)$

Table 2. Effects of SA concentration on the characteristics of nanoparticles with a fixed mass concentration ratio of sodium alginate to $\mathrm{CaCl}_{2}$ to chitosan of 1:0.22:0.15 $(n=5)$.

\begin{tabular}{cccc}
\hline SA Concentration $(\mathbf{m g} / \mathbf{m L})$ & Particles Size $(\mathbf{n m})$ & PDI $^{\text {a }}$ & Zeta Potential $(\mathbf{m V})$ \\
\hline 0.2 & $180.0 \pm 2.7$ & $0.23 \pm 0.01$ & $20.5 \pm 4.8$ \\
0.4 & $186.0 \pm 2.7$ & $0.40 \pm 0.06$ & $-9.5 \pm 0.3$ \\
0.6 & $236.5 \pm 6.6$ & $0.52 \pm 0.03$ & $-26.4 \pm 1.1$ \\
0.8 & $261.9 \pm 46.2$ & $0.71 \pm 0.11$ & $-34.1 \pm 1.3$ \\
1.0 & $293.6 \pm 14.9$ & $0.83 \pm 0.17$ & $-37.2 \pm 1.3$ \\
\hline
\end{tabular}

a PDI: polydispersity index.

\subsubsection{Effect of $\mathrm{CaCl}_{2}$ Concentration on NPs}

The effect of $\mathrm{CaCl}_{2}$ on NPs is shown in Table 3. NPs size decrease with $\mathrm{CaCl}_{2}$ concentration at $\mathrm{CaCl}_{2}$ concentrations below $0.33 \mathrm{mg} / \mathrm{mL}$, and increases with $\mathrm{CaCl}_{2}$ concentration at $\mathrm{CaCl}_{2}$ concentrations above $0.33 \mathrm{mg} / \mathrm{mL}$. In addition, the zeta potential of NPs increases with $\mathrm{Ca}^{2+}$ concentration. These phenomena can be attributed to a small amount of $\mathrm{Ca}^{2+}$ that can be bonded to the $\mathrm{G}$ fragment of SA and chelated by CS. However, excessive $\mathrm{Ca}^{2+}$ causes an increase in nanoparticle zeta potential, causing nanoparticles to repel each other. 
Therefore, a $\mathrm{CaCl}_{2}$ concentration of $0.33 \mathrm{mg} / \mathrm{mL}$ was selected to prepare the NPs with minimum size $(171.9 \pm 1.1 \mathrm{~nm})$ and appropriate zeta potential range $(-27.9 \pm 1.9 \mathrm{mV})$.

Table 3. Effects of calcium chloride concentration on nanoparticles on the characteristics of nanoparticles with a fixed mass concentration ratio of sodium alginate to $\mathrm{CaCl}_{2}$ to chitosan of 1:0.22:0.15, a SA concentration of $0.6 \mathrm{mg} / \mathrm{mL}(n=5)$.

\begin{tabular}{cccc}
\hline $\mathbf{C a C l}_{\mathbf{2}}$ Concentration $(\mathbf{m g} / \mathbf{m L})$ & Particles Size $(\mathbf{n m})$ & PDI $^{\mathbf{a}}$ & Zeta Potential $^{(\mathbf{m V})}$ \\
\hline 0.06 & $185.5 \pm 4.1$ & $0.57 \pm 0.04$ & $-38.7 \pm 1.3$ \\
0.165 & $184.2 \pm 4.0$ & $0.49 \pm 0.03$ & $-32.2 \pm 1.4$ \\
0.33 & $171.9 \pm 1.1$ & $0.50 \pm 0.00$ & $-27.9 \pm 1.9$ \\
0.66 & $246.2 \pm 4.0$ & $0.60 \pm 0.07$ & $-27.2 \pm 0.1$ \\
1.32 & $352.8 \pm 5.8$ & $0.40 \pm 0.01$ & $-20.9 \pm 0.9$ \\
\hline
\end{tabular}

a PDI: polydispersity index.

\subsubsection{Effect of CTS Concentration on NPs}

As shown in Table 4, NPs size increase with CTS concentration at CTS concentrations below $0.45 \mathrm{mg} / \mathrm{mL}$, and decreases with CTS concentration at CTS concentrations above $0.45 \mathrm{mg} / \mathrm{mL}$. NP zeta potential increased, and the PDI decreased as the CTS concentration increased. Moreover, a CTS increase above $0.6 \mathrm{mg} / \mathrm{mL}$ led to the production of aggregated particles and an opaque suspension. This might have occurred owing to CTS forming a compact membrane on the surface of nanoparticles and having a neutralising effect on the negative charge of the nanoparticles. These results indicated that a CTS concentration of $0.6 \mathrm{mg} / \mathrm{mL}$ was optimal to prepare NPs with appropriate zeta potential, minimum PDI, and smaller size.

Table 4. Effects of chitosan concentration on nanoparticles on the characteristics of nanoparticles with a fixed mass concentration ratio of sodium alginate to $\mathrm{CaCl}_{2}$ to chitosan of 1:0.22:0.15, a SA concentration of $0.6 \mathrm{mg} / \mathrm{mL}$, and $\mathrm{CaCl}_{2}$ concentration of $0.33 \mathrm{mg} / \mathrm{mL}(n=5)$.

\begin{tabular}{cccc}
\hline CTS Concentration $(\mathbf{m g} / \mathbf{m L})$ & Particles Size $(\mathbf{n m})$ & PDI $^{\text {a }}$ & Zeta Potential $(\mathbf{m V})$ \\
\hline 0.15 & $147.3 \pm 3.8$ & $0.60 \pm 0.04$ & $-32.3 \pm 0.3$ \\
0.3 & $181.8 \pm 4.1$ & $0.54 \pm 0.04$ & $-30.7 \pm 1.5$ \\
0.45 & $196.8 \pm 4.0$ & $0.59 \pm 0.01$ & $-30.6 \pm 0.5$ \\
0.6 & $191.8 \pm 3.2$ & $0.34 \pm 0.00$ & $-29.9 \pm 0.5$ \\
0.75 & $175.9 \pm 3.3$ & $0.48 \pm 0.03$ & $-29.9 \pm 0.4$ \\
\hline
\end{tabular}

a PDI: polydispersity index.

\subsection{Effect of DG1 Concentration}

As shown in Table 5, when the DG1 concentration is below $9.6 \mathrm{mg} / \mathrm{mL}$, the encapsulation efficiency (EE) and the loading capacity (LC) increase with DG1 concentration. The nanoparticle EE and LC of DG1 reached $98.09 \%$ and $18.01 \mathrm{U} / \mathrm{mg}$ at a concentration of $9.6 \mathrm{mg} / \mathrm{mL}$. When the DG1 concentration increased to $12 \mathrm{mg} / \mathrm{mL}$, the nanoparticle LC increased to $18.89 \mathrm{U} / \mathrm{mg}$, whereas the EE decreased to $90.09 \%$. When the concentration of DG1 was increased to $12 \mathrm{mg} / \mathrm{mL}$, the LC of the nanoparticles increased to $18.89 \mathrm{U} / \mathrm{mg}$, while the EE decreased to $90.09 \%$ with the occurrence of agglomeration. Moreover, when the DG1 concentration was below $7.2 \mathrm{mg} / \mathrm{mL}$, the particle size and PDI significantly increased, and zeta potential decreased as the DG1 concentration increased. When the DG1 concentration was $7.2 \mathrm{mg} / \mathrm{mL}$, the nanoparticle size was $252.4 \mathrm{~nm}$. As the DG1 concentration increased to $9.6 \mathrm{mg} / \mathrm{mL}$, the nanoparticle size increased to $366.6 \mathrm{~nm}$. This phenomenon may have occurred because DG1 is a negatively charged polymer. Therefore, to obtain nanoparticles with high EE and LC, small particle size, and steady-state, the DG1 concentration of $7.2 \mathrm{mg} / \mathrm{mL}$ was selected to prepare DG1-NPs and DG1/Cur-NPs. 
Table 5. Effects of clam heparin DG1 concentration on DG1-NPs with a fixed mass concentration ratio of sodium alginate to $\mathrm{CaCl}_{2}$ to chitosan of 1:0.22:0.15, a SA concentration of $0.6 \mathrm{mg} / \mathrm{mL}, \mathrm{a} \mathrm{CaCl}_{2}$ concentration of $0.33 \mathrm{mg} / \mathrm{mL}$, and a CTS concentration of $0.6 \mathrm{mg} / \mathrm{mL}(n=5)$.

\begin{tabular}{cccccc}
\hline $\begin{array}{c}\text { DG1 } \\
\text { Concentration }(\mathbf{m g} / \mathbf{m L})\end{array}$ & $\begin{array}{c}\text { Particles } \\
\text { Size } \mathbf{( n m )}\end{array}$ & PDI a & $\begin{array}{c}\text { Zeta } \\
\text { Potential (mV) }\end{array}$ & $\begin{array}{c}\text { Encapsulation } \\
\text { Efficiency (\%) }\end{array}$ & $\begin{array}{c}\text { Loading } \\
\text { Capacity (U/mg) }\end{array}$ \\
\hline 2.4 & $210.2 \pm 0.7$ & $0.47 \pm 0.01$ & $-31.8 \pm 1.1$ & $91.37 \pm 0.00$ & $6.06 \pm 0.00$ \\
4.8 & $248.3 \pm 8.5$ & $0.50 \pm 0.01$ & $-31.2 \pm 0.8$ & $92.37 \pm 1.62$ & $10.51 \pm 0.11$ \\
7.2 & $252.4 \pm 0.9$ & $0.49 \pm 0.03$ & $-33.8 \pm 1.0$ & $94.52 \pm 1.24$ & $13.90 \pm 0.17$ \\
9.6 & $366.6 \pm 21.1$ & $0.66 \pm 0.07$ & $-35.2 \pm 1.5$ & $98.09 \pm 0.47$ & $18.01 \pm 0.08$ \\
12 & $225.5 \pm 4.4$ & $0.51 \pm 0.03$ & $-35.2 \pm 1.6$ & $90.09 \pm 0.37$ & $18.89 \pm 0.07$ \\
\hline
\end{tabular}

a PDI: polydispersity index.

\subsection{Effect of Cur Concentration}

As shown in Table 6, nanoparticles size decreases with Cur concentration at Cur concentrations below $0.24 \mathrm{mg} / \mathrm{mL}$ and increases at Cur concentrations above $0.24 \mathrm{mg} / \mathrm{mL}$. The zeta potential of nanoparticles increases with Cur concentration. In addition, The EE of Cur decreased with Cur concentration. The EE of the nanoparticles of Cur reached a maximum of $0.3 \%$ at a concentration of $0.24 \mathrm{mg} / \mathrm{mL}$ of Cur and decreased to $0.23 \%$ when the concentration of Cur increased to 0.48 or even $0.72 \mathrm{mg} / \mathrm{mL}$. This may have occurred because the only form of the diketone group of Cur in solution is the enol, which leads to increased hydrophobicity and repels aqueous environments [30]. Therefore, the Cur concentration of $0.24 \mathrm{mg} / \mathrm{mL}$ was considered ideal for preparing DG1/Cur-NPs with high LC and small size.

Table 6. Effects of curcumin concentration on DG1/Cur-NPs with a fixed mass concentration ratio of sodium alginate to $\mathrm{CaCl}_{2}$ to chitosan of 1:0.22:0.15, a SA concentration of $0.6 \mathrm{mg} / \mathrm{mL}$, a $\mathrm{CaCl}_{2}$ concentration of $0.33 \mathrm{mg} / \mathrm{mL}$, and a CTS concentration of $0.6 \mathrm{mg} / \mathrm{mL}$, and a DG1 concentration of $7.2 \mathrm{mg} / \mathrm{mL}(n=5)$.

\begin{tabular}{cccccc}
\hline $\begin{array}{c}\text { Cur } \\
\text { Concentration (mg/mL) }\end{array}$ & $\begin{array}{c}\text { Particles } \\
\text { Size (nm) }\end{array}$ & PDI ${ }^{\mathbf{a}}$ & $\begin{array}{c}\text { Zeta } \\
\text { Potential (mV) }\end{array}$ & $\begin{array}{c}\text { Cur } \\
\text { Encapsulation } \\
\text { Efficiency (\%) }\end{array}$ & $\begin{array}{c}\text { Cur Loading } \\
\text { Capacity (\%) }\end{array}$ \\
\hline 0.06 & $465.3 \pm 32.7$ & $0.59 \pm 0.04$ & $-33.7 \pm 0.3$ & $27.90 \pm 3.33$ & $0.10 \pm 0.01$ \\
0.12 & $354.9 \pm 33.4$ & $0.62 \pm 0.06$ & $-28.5 \pm 2.0$ & $23.81 \pm 1.91$ & $0.17 \pm 0.01$ \\
0.24 & $339.7 \pm 11.2$ & $0.51 \pm 0.04$ & $-28.4 \pm 1.3$ & $21.04 \pm 2.61$ & $0.30 \pm 0.04$ \\
0.48 & $1840.3 \pm 223.4$ & $1.00 \pm 0.00$ & $-27.9 \pm 0.6$ & $8.24 \pm 0.38$ & $0.23 \pm 0.01$ \\
0.72 & $2079.0 \pm 162.8$ & $1.00 \pm 0.00$ & $27.1 \pm 0.6$ & $5.57 \pm 0.77$ & $0.23 \pm 0.03$ \\
\hline
\end{tabular}

a PDI: polydispersity index.

\subsection{Characterisation of Clam Heparinoid Nanoparticles}

\subsubsection{SEM Analysis}

SEM images of NPs, DG1-NPs, and DG1/Cur-NPs are shown in Figure 1. NPs, DG1NPs, and DG1/Cur-NPs were all spherical or sphere-like in shape. Compared with NPs and DG1-NPs, the particle size of DG1/Cur-NPs was distinctly bigger, and an agglomerated morphology was observed.

\subsubsection{FITR Analysis}

FTIR was used to characterise the interactions between DG1 or Cur and polymers in the nanoparticles. As shown in Figure 2, the FTIR spectra of DG1 showed broadband at $3458 \mathrm{~cm}^{-1}$, which corresponded to $\mathrm{O}-\mathrm{H}$ and $\mathrm{N}-\mathrm{H}$ stretching. The band at $2987 \mathrm{~cm}^{-1}$ represented the $\mathrm{C}-\mathrm{H}$ stretching of the aliphatic hydrocarbon side chain. The peak for the amide group $\mathrm{C}=\mathrm{O}$ asymmetric stretching and $\mathrm{N}-\mathrm{H}$ angle vibration occurred at $1627 \mathrm{~cm}^{-1}$. The band at $1427 \mathrm{~cm}^{-1}$ corresponded to the C-N stretching of the amide of the ether bond, whereas the peak at $1261 \mathrm{~cm}^{-1}$ was attributed to the $\mathrm{S}=\mathrm{O}$ asymmetric stretching 
of the sulfonic acid group. The band at $1151 \mathrm{~cm}^{-1}$ corresponded to the $\mathrm{C}-\mathrm{O}$ stretching of cyclopropyl ether. The band at $1051 \mathrm{~cm}^{-1}$ represented the $\mathrm{C}-\mathrm{O}-\mathrm{C}$ and $\mathrm{C}-\mathrm{OH}$ stretching of the pyranose ring ether bond, whereas the peaks at 950 and $887 \mathrm{~cm}^{-1}$ are the characteristic peaks of heparin [8,31]. In the NPs spectra, the bands at 3458, 2987, 1627, 1427, 1261,1151, and $1051 \mathrm{~cm}^{-1}$ shifted slightly to $3439,2964,1625,1427,1234,1093$, and $1043 \mathrm{~cm}^{-1}$, respectively, and the respective maximum absorbing peaks at 3458, 1627, 1427, 1261, 1151, and $1051 \mathrm{~cm}^{-1}$ became lower in comparison to those in DG1. Physical mixture 1 is a mixture of clam heparin and NPs mixed in a dosage ratio. According to the FTIR spectra of Physical mixture 1 and DG1-NPs, the FTIR spectra of Physical mixture 1 is a superposition of DG1 and NPs peaks. The DG1-NPs and NPs spectra were similar. These results were consistent with those of Eleraky et al., which suggests that the micelle formation in the nanoparticles reduced some signals [32].

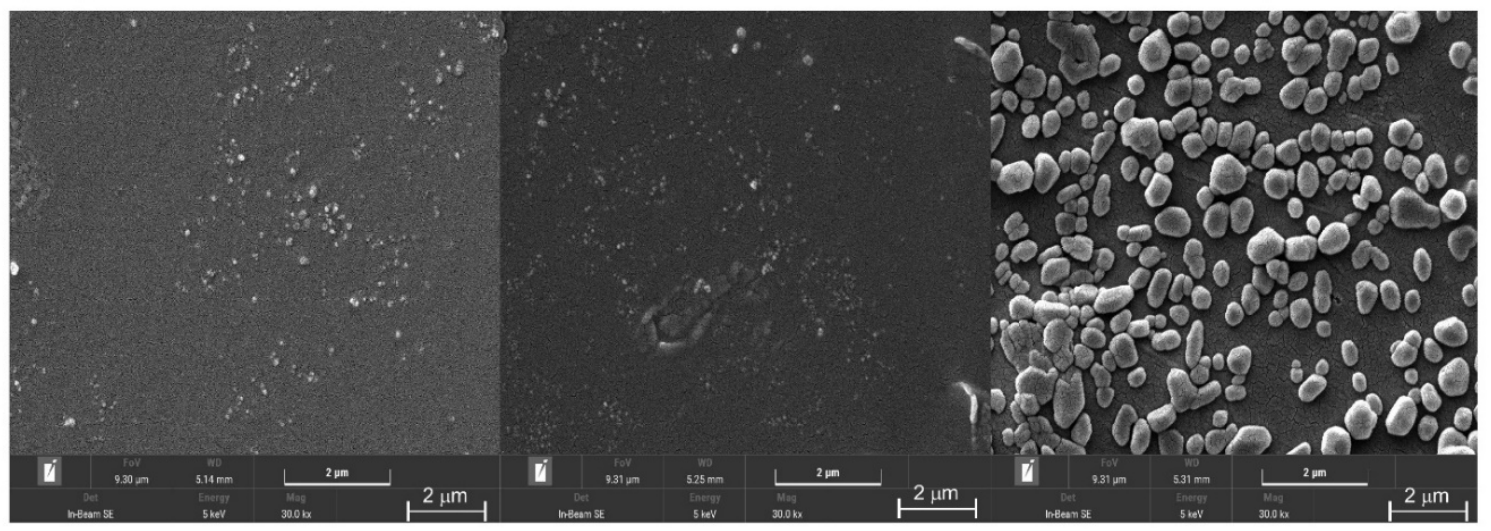

A - NPs

$B$ - DG1-NPs

C- DG1/Cur-NPs

Figure 1. SEM analysis of NPs, DG1-NPs, and DG1/ Cur-NPs.

A

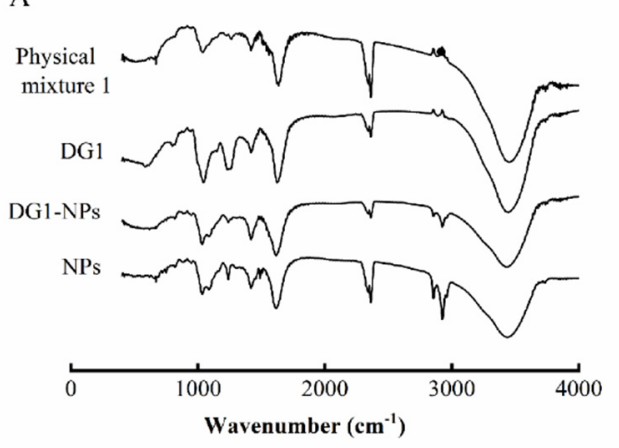

B

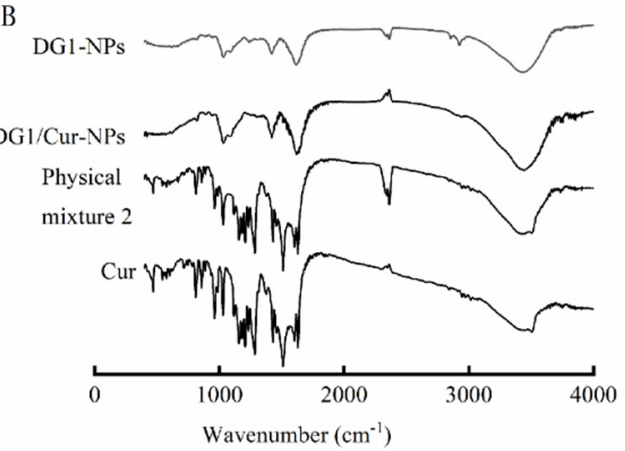

Figure 2. Infrared spectral analysis of DG1-NPs (A) and DG1 / Cur-NPs (B). Physical mixture 2: a formulated mixture of Cur and DG1-NPs; Physical mixture 1: a formulated mixture of DG1 and NPs. 
In the Cur spectra, the broadband at $3508 \mathrm{~cm}^{-1}$ was attributed to the $\mathrm{O}-\mathrm{H}$ stretching of the hydroxyl group. The peaks at 1631 and $1510 \mathrm{~cm}^{-1}$ corresponded to the stretching and bending vibrations of $\mathrm{C}=\mathrm{C}$ and $\mathrm{C}=\mathrm{O}$, respectively. The peaks at 1602, 1429, and $1286 \mathrm{~cm}^{-1}$ were attributed to the stretching vibration of the benzene ring skeleton, bending vibration of the alkene $\mathrm{C}-\mathrm{H}$ plane, and stretching vibration of aromatic $\mathrm{C}-\mathrm{O}$, respectively. The peaks at 1163 and $808 \mathrm{~cm}^{-1}$ were associated with the aromatic C-H bending vibration, whereas the peak at $1029 \mathrm{~cm}^{-1}$ corresponded to the C-O-C stretching vibration [33]. After complexation with chitosan, alginate, and DG1, the bands at 3508, 1631, and $1429 \mathrm{~cm}^{-1}$ shifted slightly to 3448,1624 , and $1419 \mathrm{~cm}^{-1}$, respectively. The bands at $1602,1286,1510$, 1163,1029 , and $808 \mathrm{~cm}^{-1}$ disappeared. Physical mixture 2 is a formulated mixture of Cur and DG1-NPS. After the addition of chitosan, alginate, and DG1, the peaks at 3508, 1631, $1602,1510,1429,1286,1163,1029$, and $808 \mathrm{~cm}^{-1}$ in the spectra of Cur alone remained in the spectra of Physical mixture 2. They shifted slightly to 3456, 1629, 1604, 1510, 1429, 1282, 1155,1029 , and $813 \mathrm{~cm}^{-1}$, respectively. These results suggest that the micelle formation in the nanoparticles led some signals to disappear, demonstrating the Cur entrapment in the DG1/Cur-NPs at the molecular level and implies that micelle formation during the nanoparticle preparation did not cause the breakdown of the Cur structure [27,34].

In summary, these findings demonstrate the entrapment of DG1 and Cur in the clam heparinoid nanoparticles at the molecular level.

\subsubsection{DSC Analysis}

DSC is widely used for thermal analysis because when a new nanoparticle is formed, the melting and boiling points of the original sample are changed [35]. As shown in Figure 3, a sharp endothermic peak was observed at $87^{\circ} \mathrm{C}$, corresponding to the melting point of pure DG1, and an exothermic peak occurred at $279{ }^{\circ} \mathrm{C}$. In NPs, there was an endothermic peak at $72{ }^{\circ} \mathrm{C}$ and an exothermic peak at $258^{\circ} \mathrm{C}$. DG1-NPs showed an endothermic peak at $65{ }^{\circ} \mathrm{C}$ and an exothermic peak at $259{ }^{\circ} \mathrm{C}$. Physical mixture 1 showed an endothermic peak at $101^{\circ} \mathrm{C}$ and an exothermic peak at $257^{\circ} \mathrm{C}$. For exothermic peaks, the peak values were in the following order: DG1 > Physical mixture 1 > NPs > DG1-NPs; whereas the exothermic peaks of DG1-NPs mixture, NPs, and DG1-NPs were all approximately $254{ }^{\circ} \mathrm{C}$. The DSC thermogram of DG1 was more similar to that of Physical mixture 1 than that of DG1-NPS, which indicated the successful preparation of DG1-NPs.

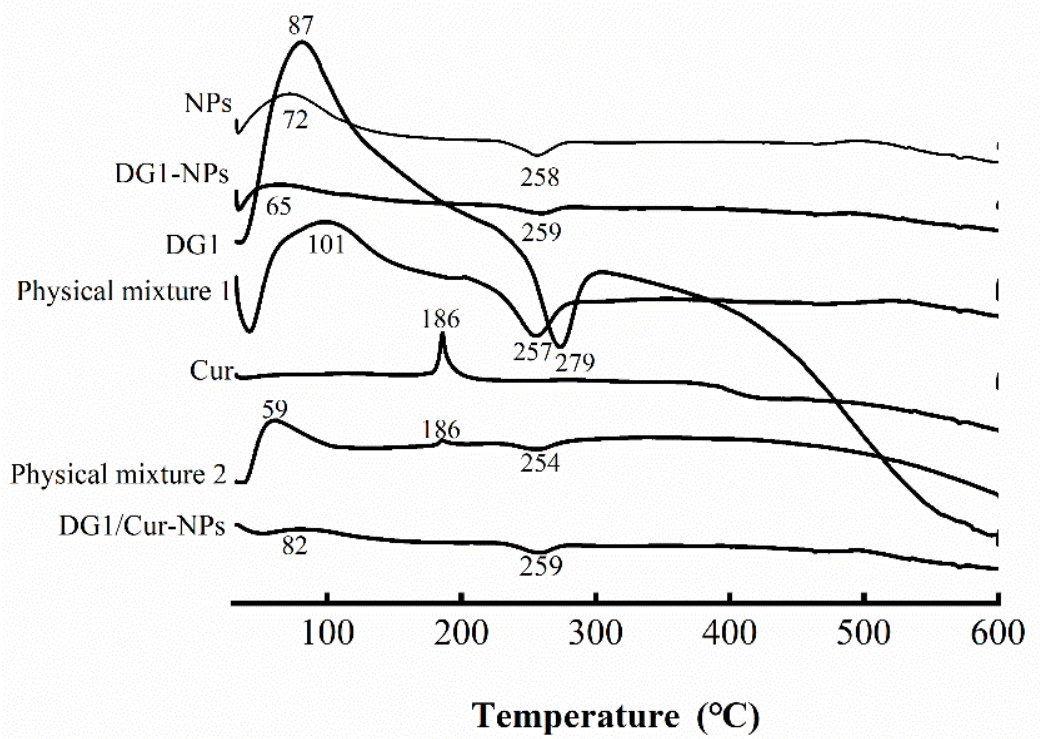

Figure 3. Differential scanning calorimetry (DSC) analysis of DG1-NPs and DG1/Cur-NPs. Physical mixture 2: a formulated mixture of Cur and DG1-NPs; Physical mixture 1: a formulated mixture of DG1 and NPs. 
In addition, for Cur, a sharp endothermic peak was observed at $186{ }^{\circ} \mathrm{C}$, which is the melting point of pure Cur [36]. In Physical mixture 2, there were endothermic peaks at $59{ }^{\circ} \mathrm{C}$ and $186{ }^{\circ} \mathrm{C}$ and an exothermic peak at $254{ }^{\circ} \mathrm{C}$. In contrast, no endothermic (melting) peak of Cur was observed in the DSC thermogram of DG1/Cur-NPs. The reduced intensity of the peak at $188{ }^{\circ} \mathrm{C}$ and the appearance of new peaks at $166{ }^{\circ} \mathrm{C}$ and $170{ }^{\circ} \mathrm{C}$ confirmed the reduced crystallinity of Cur and the formation of a new polymorph during the crystallisation procedure, as reported by Pantwalawalkar [37]. Sadeghi et al. reported that the melting peak of Cur disappeared in solid dispersion systems of Cur and PVP, which indicated that Cur was in an amorphous state in the precipitated samples [38]. Therefore, the absence of the endothermic melting peak of Cur suggested that Cur was encapsulated in the nanoparticles and was present in an amorphous form as a molecular dispersion or a disordered crystalline phase within the nanoparticle matrix.

\subsection{Effect of DG1-NPs and DG1/Cur-NPs on Collagen plus Epinephrine-Induced Acute Pulmo-nary Thrombosis in Mice}

Both epinephrine and collagen are potent platelet activators and cause significant platelet aggregation, and epinephrine has a significant vasoconstrictive effect [39]. A previous study reported that the injection of collagen and epinephrine caused the decrease in platelet count, aggregation of platelets in lung blood vessels, and death of mice owing to respiratory failure [40]. In addition, the thrombus produced in the mice lungs increased their lung mass, which increased their respective lung index.

The in vivo prevention of pulmonary thromboembolism in mice by clam heparinoid nanoparticles was investigated. As shown in Table 7, the protective effect of HP sodium and DG1 reached 40\%, and that of DG1/Cur-NPs and DG1-NPs were both $50 \%$, which is 1.25-fold higher than that of DG1 solution after oral administration. In addition, the lung coefficients of group $\mathrm{M}$ increased significantly $(p<0.01)$. In contrast, Lung index is the weight of the mouse lung as a percentage of the mouse's body weight. The lung index of the DG1, DG1-NPs, and DG1/Cur-NPs groups for pulmonary embolism decreased significantly $(p<0.01)$. The lung coefficients of the DG1, DG1/Cur-NPs, and DG1-NPs groups were reduced sequentially. These results indicated that the capacity of clam heparinoid DG1 to protect mice against pulmonary embolism is comparable to that of heparin sodium at the same dose. That is, chitosan-alginate nanoparticles can improve the oral protective effect of clam heparinoid DG1 against collagen plus epinephrine-induced acute pulmonary thrombosis in mice. Moreover, NPs protected 10\% of the mice from acute pulmonary embolism, and reduced lung index indicated that chitosan and SA have a slightly antithrombotic effect. Cur does not synergise with DG1 to exert antithrombotic effects, which may have occurred because the dose of Cur was low (approximately $0.12 \mathrm{mg} / \mathrm{kg}$ ). Shi et al. also reported a thrombosis inhibition rate of $60.31 \%$ for Cur injected intraperitoneally at $50 \mathrm{mg} / \mathrm{kg}$, comparable to that of aspirin gavaged at an equivalent dose $(63.59 \%)$ in a rat carotid artery thrombosis model [41].

Table 7. Effects of oral administration of different heparin nanoparticles on pulmonary thromboembolism and pulmonary coefficient $(n=10)$.

\begin{tabular}{ccc}
\hline Group & Protection Effect (\%) & Iung Index \\
\hline $\mathrm{K}^{\mathrm{b}}$ & - & $0.62 \pm 0.08$ \\
$\mathrm{M}^{\mathrm{b}}$ & 0 & $1.06 \pm 0.30 \#^{\mathrm{a}}$ \\
$\mathrm{Y}^{\mathrm{b}}$ & 40 & $0.91 \pm 0.22$ \\
$\mathrm{NPs}^{\mathrm{a}}$ & 10 & $0.95 \pm 0.24$ \\
DG1 & 40 & $0.80 \pm 0.26^{* * \mathrm{a}}$ \\
DG1-NPs & 50 & $0.77 \pm 0.15^{* * \mathrm{a}}$ \\
DG1/Cur-NPs & 50 & $0.79 \pm 0.18^{* * \mathrm{a}}$
\end{tabular}

a Statistical significance: ${ }^{* *} p<0.01$, as compared with model (M) group. \#\# $p<0.01$, as compared with blank control (K) group. ${ }^{b} \mathrm{~B}$ group: the blank control group gavaged with water; $\mathrm{M}$ group: the model group gavaged with water and treated with collagen plus epinephrine; Y group: the positive control group gavaged with sodium heparin and treated with collagen plus epinephrine. 
To further confirm the prevention of pulmonary thromboembolism by the clam heparinoid treatment, lung conditions were photographed, and cross-sections of mice lungs at similar locations were observed based on HE staining. Lungs from mice in group $\mathrm{M}$ showed many thrombi (Figure 4A). HE staining of lungs in group $\mathrm{M}$ showed thrombus in the capillaries, capillary congestion and oedema in the alveolar wall, and infiltration of lymphocytes and histiocytes, interspersed with varying amounts of inflammatory cells in the lungs of mice with pulmonary embolism (Figure 4B). Consistent with the protection effect and Iung index results, the treatment with DG1, DG1-NPs, DG1/Cur-NPs, sodium heparin, and NPs prevented these symptoms of acute pulmonary embolism from occurring in the lung of mice to different degrees (Figure $4 \mathrm{~A}, \mathrm{~B}$ ).

A

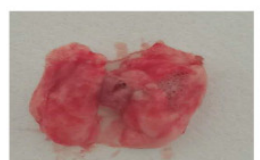

K

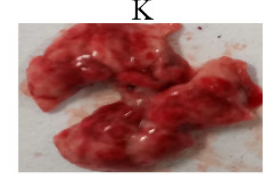

NPs

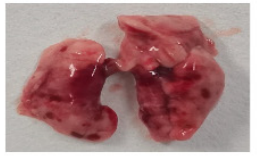

DG1/Cur-NPs

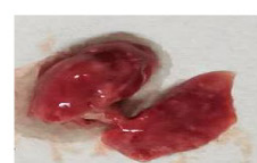

M

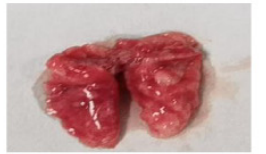

DG1

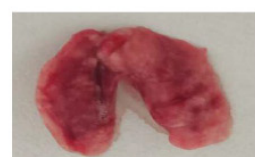

Y

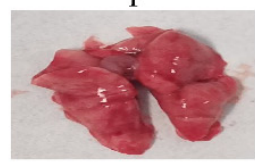

DG1-NPs
B

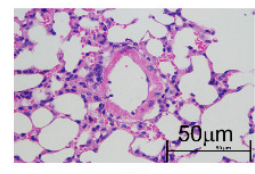

K

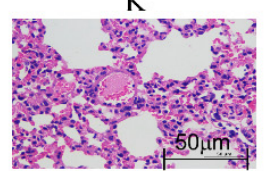

NPs

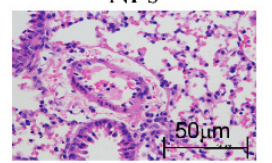

DG1/Cur-NPs

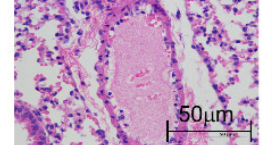

$\mathrm{M}$

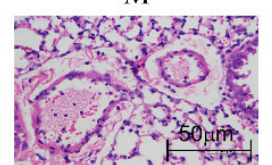

DG1

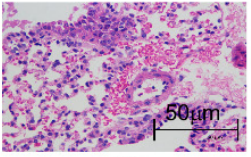
$\mathrm{Y}$

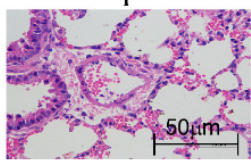

DG1-NPs

Figure 4. (A) Lung tissues of mice from each group, and respective (B) lung tissue sections (HE staining $\times 400$ ). B group: the blank control group gavaged with water; $M$ group: the model group gavaged with water and treated with collagen plus epinephrine; Y group: the positive control group gavaged with sodium heparin and treated with collagen plus epinephrine.

\section{Discussion}

Low molecular weight clam heparinoid DG1 with a molecular weight of $24.48 \mathrm{kDa}$ are derived from vitamin catalytic free-radical depolymerisation of native clam heparinoid G2. We chose DG1 to prepare oral antithrombotic nanoparticles because of its strong oral antithrombotic activity and low molecular weight [9]. In this study, we analysed physicochemical properties that impact the preparation of DG1 nanoparticles. The results showed that DG1 is a water-soluble anionic polymer with a high content of sulphate groups and uronic acid and a high initial degradation temperature.

To prepare nanoparticles with small particle size, suitable potential, and high encapsulation rate and LC, we performed single-factor optimisation experiments on the formulation parameters of nanoparticles. The results showed that $0.6 \mathrm{mg} / \mathrm{mL} \mathrm{SA}, 0.33 \mathrm{mg} / \mathrm{mL}$ $\mathrm{CaCl} 2,0.6 \mathrm{mg} / \mathrm{mL}$ CTS, $7.2 \mathrm{mg} / \mathrm{mL}$ DG1, and $0.24 \mathrm{mg} / \mathrm{mL}$ Cur were optimal formulation parameters for the preparation of clam heparinoid nanoparticles. Under these conditions, we prepared empty nanoparticles, NPs, DG1 only nanoparticles, DG1-NPs, and DG1 and Cur compliant nanoparticles, DG1/Cur-NPs. NPs presented a particle size of $191.8 \mathrm{~nm}$. In comparison, Azevedo et al. [42] reported a mean size of approximately $168 \mathrm{~nm}$ for nanoparticles using similar methodologies and materials. This may be related to each solution component's $\mathrm{pH}$ and final concentration mass ratio used to prepare these two nanoparticles. DG1-NPs presented particle size, zeta potential, PDI, LC, and EE of $210.2 \pm 0.7 \mathrm{~nm},-35.2 \pm 1.5 \mathrm{mV}, 0.66 \pm 0.07,94.52 \pm 1.24 \%$, and $13.90 \pm 0.17 \mathrm{U} / \mathrm{mg}$, respectively. Compared with the alginate/chitosan nanoparticles of vitamin B2 and chitosan/alginate nanoparticles containing curcumin diethyl disuccinate, DG1-NPs presented higher EE and more negative zeta potential, likely attributable to the water solubility and 
negative charge of DG1 [26,42]. The DG1/Cur-NPs presented particle size, zeta potential, and PDI of $339.7 \pm 11.2 \mathrm{~nm},-28.5 \pm 2.0 \mathrm{mV}$, and $0.51 \pm 0.04$. The LC and EE of DG1 were $86.98 \pm 1.13 \%$ and $13.10 \pm 0.17 \mathrm{U} / \mathrm{mg}$, whereas those of Cur were $21.04 \pm 2.61 \%$ and $0.30 \pm 0.04 \%$, respectively. Compared with the curcumin diethyl disuccinate-only nanoparticles [27], the DG1/Cur-NP size was smaller and presented a lower Cur embedding rate and LC. In addition, compared with DG1-NPs, the particle size of DG1 was significantly larger, whereas its embedding rate and drug LC were lower. Therefore, it is necessary to further increase the DG1 and Cur LC of DG1/Cur-NPS by adjusting the pH of the solution, for instance, using surfactants.

In addition, we have characterised the nanoparticles. The results of SEM, FITR, and DSC indicated the entrapment of DG1 and Cur in the clam heparinoid nanoparticles at the molecular level, and Cur was loaded in the amorphous phase within the nanoparticle matrix. These results suggested that Cur is a hydrophobic compound, which is not highly soluble under neutral, acidic conditions [31,43]. However, it can be encapsulated in chitosan/alginate nanoparticles.

One of the characteristics of pulmonary embolism is "three highs", i.e., high morbidity, high misdiagnosis, and high mortality [3]. The mice pulmonary embolism model can simulate pulmonary embolism well and has the characteristics of easy modeling and significant effect. As a classical antithrombotic, aspirin showed a protective effect by $50-80 \%$ at a dose of $20 \mathrm{mg} / \mathrm{kg}$ and above [44-46]. Tang et al. discovered that the protective effect of enoxaparin-loaded LPHN2 was 50.0\%, 2.99-fold higher than that of enoxaparin solution $(16.70 \%)$ after oral administration, indicated that lipid-polymer hybrid nanoparticles are effective in improving oral absorption and the inhibition effect of enoxaparin against thrombin-induced thrombosis [14]. Furthermore, the Viscera index can be used to detect pathological changes in animals [47]. Shen et al. discovered that aspirin eugenol ester significantly reduces lung coefficients in mice with pulmonary embolism $(0.98 \pm 0.07 \%$ vs. $0.84 \pm 0.04 \%$ ) [48]. In this study, we observed that the protective effect of DG1/CurNPs and DG1-NPs were both 50\%, which is 1.25 -fold higher than that of DG1 solution. The lung coefficients of pulmonary embolism mice in the DG1/Cur-NPs and DG1-NPs groups were slightly lower than those in the DG1 group $(0.77 \pm 0.15 \%$ and $0.79 \pm 0.18 \%$ vs $0.80 \pm 0.26 \%$ ). Thus, our results suggest that the chitosan/alginate nanoparticles enhanced the oral antithrombotic activity of DG1. However, Cur did not further enhance this effect under the conditions of this study. Nonetheless, studying their oral antithrombotic mechanisms at the molecular and genetic levels is important. The oral antithrombotic activity of nanoparticles can also be further evaluated by mice carrageenin-induced thrombosis model, rat carotid thrombosis model, rat venous thrombosis model, and other animal models.

Chitosan/alginate nanoparticles by ionotropic pre-gelation are characterised by a compact chitosan film overlying the calcium-alginate pre-gel, enabling controlled release and strong absorption of nanoparticles in the intestine [49,50]. However, the in vitro simulated digestion, Cao2 cell model, and other means were not used in this study to investigate the basic characterisations in terms of release of nanoparticles, biocompatibility, and disponibility of DG1 or Cur after oral administration, which is the next step we need to investigate.

\section{Materials and Methods}

\subsection{Materials}

Clam heparinoid DG1 was prepared as described by Chen et al. [51]. Chitosan (91.5\% degree of deacetylation), alginic acid sodium salt (analytical research (AR) grade, $98 \%$ degree of purity), Cur (Biological Grade (BR), 98\% degree of purity), and collagen (isolation from cow heel, and molecular weight greater than 300,000 g/mol) were purchased from Shanghai Yuanye Biological Co., Ltd. (Shanghai, China). AR grade acetic acid, hydrochloric acid, sodium hydroxide, and calcium chloride were obtained from Xilong Science Co., Ltd. (Guangzhou, China). Epinephrine was purchased from Sanma Veterinary Medicine Co., Ltd. (Harbin, China). 
Male Kunming mice (20-22 g) were provided by Zhuhai Bestest Biotech Co., Ltd. (Zhuhai, China). The animals were housed under a $12 \mathrm{~h}$ light-dark cycle at a constant ambient temperature of $22-25{ }^{\circ} \mathrm{C}$ and humidity of $55 \pm 5 \%$, with normal chow and water ad libitum. They were allowed to acclimatise for one week before the experiments began. All animal care and experimental protocols were strictly followed according to the guidelines of the Laboratory Animal Center of Guangdong Ocean University and were approved by the Institutional Animal Care and Use Committee of Guangdong Ocean University (No. GDOU-LAE-2021-003).

\subsection{Determination of Physicochemical Properties of DG1}

The uronic acid content of DG1 was determined by a modified sulphate-carbazole method [52]. The sulphate ester content of DG1 was estimated according to the $\mathrm{Gel}-\mathrm{BaCl}_{2}$ colorimetric method [53].

A solution of clam heparinoid DG1 at a $0.01 \mathrm{mg} / \mathrm{mL}$ concentration was prepared and filtered through a $0.2 \mu \mathrm{m}$ membrane. The particle size and zeta potential of DG1 were determined using a Zetasizer model Nano-ZS (Nano-ZS90, Malvern Instruments, England).

Thermal stability analysis of DG1 was carried out using a simultaneous thermal analyser (TA Q2000, TA Instruments, USA). The samples were analysed for thermal weight loss (TG) in the temperature range $20-600{ }^{\circ} \mathrm{C}$ under $\mathrm{N}_{2}$ atmosphere at a $50 \mathrm{~mL} / \mathrm{min}$ flow rate and a ramp rate of $10^{\circ} \mathrm{C} / \mathrm{min}$.

\subsection{Preparation and Optimisation of Clam Heparinoid Nanoparticles}

Clam heparinoid nanoparticles were prepared by the ionic cross-linking method, as reported by Bhunchu et al. [27]. For that, the clam heparinoid DG1 solution (1 mL) and Cur ethanol solution $(1 \mathrm{~mL})$ were added dropwise to the SA solution $(20 \mathrm{~mL})$ using a peristaltic pump (HN-2, Shanghai Huxi Analytical Instrument Factory Co. Ltd., Shanghai, China) at an addition rate of $5 \mathrm{rpm}$ under mechanical stirring at $1000 \mathrm{rpm}$ for $10 \mathrm{~min}$, followed by dropwise addition of calcium chloride solution $(4 \mathrm{~mL})$ and continued stirring for $10 \mathrm{~min}$. After sonication at a frequency of $40 \mathrm{kHz}$ and sonic power of $20 \mathrm{~W}$ (JP-040S, Shenzhen Clean Union Cleaning Equipment Co. Ltd., Shenzhen, China) for $5 \mathrm{~min}, 4 \mathrm{~mL}$ of CTS acetic acid solution $(1 \%, v / v)$ at varying concentrations were added dropwise to the resultant calcium-alginate pre-gel with continuous stirring at $1000 \mathrm{rpm}$ for $10 \mathrm{~min}$, followed by standing for $20 \mathrm{~min}$, centrifugation at $3000 \mathrm{rpm}$ for $10 \mathrm{~min}$ to remove the insoluble material, and removal of the supernatant, which was freeze-dried to produce the DG1/Cur-NPs. The DG1-NPs were prepared by omitting the Cur solution, and NPs were prepared by omitting the Cur and DG1 solutions.

The NPS characteristics were examined in formulations using various concentrations of SA, calcium chloride, and CTS. Subsequently, the characteristics of DG1-NPs and DG1/Cur-NPs were examined in formulations using various concentrations of DG1 and Cur, respectively. We investigated SA concentration of $0.2,0.4,0.6,0.8,1.2$, and $1.6 \mathrm{mg} / \mathrm{mL}$; calcium chloride concentrations of $0.033,0.066,0.165,0.33,0.66,1.32,1.98$, and $2.64 \mathrm{mg} / \mathrm{mL}$; CTS concentrations of $0.15,0.3,0.45,0.6,0.75,0.9,1.05$, and $1.2 \mathrm{mg} / \mathrm{mL}$; DG1 concentrations of 2.4, 4.8, 7.2, 9.6, 12, and $24 \mathrm{mg} / \mathrm{mL}$; and Cur concentrations of 0.03, 0.06, 0.12, 0.24, 0.48, 0.96 , and $1.2 \mathrm{mg} / \mathrm{mL}$. When one parameter was varied, the others remained constant. The selection of the optimum formulation was based on the particle size, size distribution (PDI), zeta potential, encapsulation efficiency, and loading capacity of the nanoparticles.

\subsection{Characterisation of Clam Heparinoid Nanoparticles}

The particle size and size distribution based on the PDI and zeta potential were determined using a Zetasizer Nano-ZS model (Nano-ZS90, Malvern Instruments, England). Subsequently, a small number of nanoparticles were placed on an aluminium foil sheet, dried, and sprayed with gold treatment. The morphologies of NPs, DG1-NPs, and DG1/Cur-NPs were then visualised by SEM (EM-7610-F, Japan Electronics Corporation, Japan). 
A $20 \mathrm{~mL}$ aqueous solution containing $10 \mathrm{mg}$ of lyophilised nanoparticles was placed in a $25 \mathrm{~mL}$ volumetric flask. After the $\mathrm{pH}$ of the supernatant was adjusted to 6.5 with $2 \mathrm{~mol} / \mathrm{L}$ $\mathrm{HCl}$ solution (using distilled water), the supernatant was sonicated at $500 \mathrm{~W}$ and $100 \mathrm{~Hz}$ for $10 \mathrm{~min}$. Subsequently, $6 \mathrm{~mL}$ of this solution was placed in a $10 \mathrm{~mL}$ volumetric flask, which was then filled with distilled water, and the potency of the clam heparinoid DG1 in DG1/Cur-NPs and DG1-NPs was determined by the azure A method [54]. For that, $1 \mathrm{~mL}$ of this solution was mixed with $4 \mathrm{~mL}$ of ethanol, and the amount of Cur in DG1/Cur-NPs was assayed as described by Ma et al. [55] (with modifications). The encapsulation efficiency was calculated from the amount of DG1 or Cur in the nanoparticles as a percentage of the total amount of DG1 or Cur initially added to the formulation. The loading capacity was calculated from the amount of DG1 or Cur in the nanoparticles as a percentage of the total dry mass. The equations were as follows:

Encapsulation efficiency $(\%)=$ DG1 or Cur in solution $\times 100 \% /$ DG1 or Cur initial

Loading capacity $=$ DG1 or Cur in solution $\times 100 \% /$ total dry mass of nanoparticles

The interaction and compatibility of DG1 or Cur with other components in the DG1NPs and DG1/Cur-NPs formulation, respectively, were analysed based on the FTIR spectra measured on a Bruker Tensor 27 FTIR spectrometer using the OPUS 7.5 software. The samples were dried under an infrared lamp for $2 \mathrm{~h}$, mixed with $\mathrm{KBr}$, grounded, and pressed into $1 \mathrm{~mm}$ pellets for FTIR spectral analysis at $4000-400 \mathrm{~cm}^{-1}$.

The physical state of DG1 or Cur in the nanoparticles was analysed by a simultaneous thermal analyser (TA Q2000, TA Instruments, USA). An inert atmosphere was maintained by purging nitrogen at a $20 \mathrm{~mL} / \mathrm{min}$ flow rate. The instrument conditions followed the method described by Murthy et al. with modifications [56]. An appropriate amount of lyophilised nanoparticles was sealed in an aluminium pan and scanned at $30-600^{\circ} \mathrm{C}$, at a heating rate of $10^{\circ} \mathrm{C} / \mathrm{min}$.

\subsection{Effect of DG1-NPs and DG1/Cur-NPs on Collagen Plus Epinephrine-induced Acute Pulmonary Thrombosis in Mice}

The antithrombotic activity of DG1-NPs and DG1/Cur-NPs was evaluated by establishing an acute pulmonary embolism model in mice, as reported by Choi et al. [46]. The experimental mice were randomly divided into seven groups $(n=10)$, namely blank (B); sodium heparin (Y); model (M); DG1; NPs; DG1-NPs; and DG1/Cur-NPs groups. Except for group B, the other groups were gavaged with NPS, sodium heparin, DG1, DG1-NPs, and DG1/Cur-NPs at a single dose of $5560 \mathrm{U} / \mathrm{k}$. Two hours after administration, all groups were intravenously injected with $10 \mathrm{~mL} / \mathrm{kg}$ of a mixture of collagen $(1 \mathrm{mg} / \mathrm{mL})$ and epinephrine $(0.1 \mathrm{mg} / \mathrm{mL})$ via the tail vein to induce hind limb paralysis or death. The number of dead or paralysed mice was recorded within $20 \mathrm{~min}$. The results show a percentage of protection. All surviving mice were sacrificed immediately after the experiment. All mice were dissected. Their lung tissues were collected, washed several times with saline, placed on clean filter paper to absorb the water, weighed, photographed, and then stained in HE sections, as reported by Gupta et al. [44] and Men et al. [57].

The equation of Lung index was Lung index $=(\mathrm{Wl} / \mathrm{Wb}) \times 100 \%$, where $\mathrm{Wl}$ is the weight of the mouse lung and $\mathrm{Wb}$ is the weight of the mouse.

\subsection{Statistical Analysis}

The results are expressed as mean \pm standard deviation. The experimental data were subjected to analysis of variance for a completely random design, and three samples were prepared for each assay. Data processing was performed using SPSS 17 and Origin 8.

\section{Conclusions}

Our results demonstrate that the molecular weight of heparin impacts its antithrombotic activity. Furthermore, molecular weight is an essential chemical characteristic for 
clam heparinoids administered by the oral routine. Further, DG1 had better absorption and antithrombotic activities than G2. Considering the large molecular weight of G2, the medium-molecular-weight clam heparinoid DG1 seems to be an attractive choice as an oral antithrombotic agent to prevent thrombotic disease.

Author Contributions: G.-L.C. carried out the experiments and analysed the data; G.-L.C. prepared the paper; H.-Y.C. contributed to the bioassay; S.-Y.Z. designed the work and gave final approval of the version published; J.-P.C., R.L., X.-J.J., X.-F.L. and B.-B.S. critically revised the manuscript. All authors have read and agreed to the published version of the manuscript.

Funding: This work was supported in part by the National Key Research and Development Project (2019YFD0902005), Key-Area Research and Development Program of Guangdong Province (2020B1111030004), the Science and Technology Program of Zhanjiang City (2019A01015), Guangdong Province ordinary universities characteristic innovation project ( 2020KTSCX051), the Science and Technology Development Program of Shenzhen City, China (JCYJ20170818111335796, PT202001-17) and the Innovative Team Program of High Education of Guangdong Province (2021KCXTD021).

Institutional Review Board Statement: The study protocol was approved by the ethics committee of the Guangdong Ocean University (GDOU-LAE-2021-003) (Guangdong, China).

Data Availability Statement: The data presented in this study are available on request from the corresponding author. The data are not publicly available due to public availability violating the consent given by research participants.

Conflicts of Interest: The authors declare no conflict of interest.

\section{References}

1. Osinbowale, O.; Ali, L.; Chi, Y.W. Venous thromboembolism: A clinical review. Postgrad. Med. 2010, 122, 54-65. [CrossRef] [PubMed]

2. Raskob, G.E.; Angchaisuksiri, P.; Blanco, A.N.; Buller, H.; Gallus, A.; Hunt, B.J.; Hylek, E.M.; Kakkar, A.; Konstantinides, S.-V.; McCumber, M.; et al. Thrombosis: A major contributor to global disease burden. Arterioscler. Thromb. Vasc. Biol. 2014, 34, 2363-2371. [CrossRef] [PubMed]

3. Di Nisio, M.; van Es, N.; Büller, H.R. Deep vein thrombosis and pulmonary embolism. Lancet 2016, 388, 3060-3073. [CrossRef]

4. Fang, G.; Tang, B. Advanced delivery strategies facilitating oral absorption of heparins. Asian J. Pharm. Sci. 2020, 15, 449-460. [CrossRef]

5. Neves, A.-R.; Correia-da-Silva, M.; Sousa, E.; Pinto, M. Strategies to Overcome Heparins' Low Oral Bioavailability. Pharmaceuticals 2016, 9, 37. [CrossRef]

6. Ishihara, M.; Nakamura, S.; Sato, Y.; Takayama, T.; Fukuda, K.; Fujita, M.; Murakami, K.; Yokoe, H. Heparinoid Complex-Based Heparin-Binding Cytokines and Cell Delivery Carriers. Molecules 2019, 24, 4630. [CrossRef]

7. Oduah, E.I.; Linhardt, R.J.; Sharfstein, S.T. Heparin: Past, Present, and Future. Pharmaceuticals 2016, 9, 38. [CrossRef]

8. Du, Z.; Jia, X.; Chen, J.; Zhou, S.; Chen, J.; Liu, X.; Cao, X.; Zhong, S.; Hong, P. Isolation and Characterization of a Heparin-Like Compound with Potent Anticoagulant and Fibrinolytic Activity from the Clam Coelomactra antiquata. Mar. Drugs 2019, 18, 6. [CrossRef]

9. Chen, G.; Zeng, R.; Wang, X.; Cai, H.; Chen, J.; Zhong, Y.; Zhong, S.; Jia, X. Antithrombotic Activity of Heparinoid G2 and Its Derivatives from the Clam Coelomactra antiquata. Mar. Drugs 2022, 20, 50. [CrossRef]

10. Shah, B.-H.; Nawaz, Z.; Pertani, S.-A.; Roomi, A.; Mahmood, H.; Saeed, S.-A.; Gilani, A.-H. Inhibitory effect of curcumin, a food spice from turmeric, on platelet-activating factor- and arachidonic acid-mediated platelet aggregation through inhibition of thromboxane formation and $\mathrm{Ca}^{2+}$ signaling. Biochem. Pharmacol. 1999, 58, 1167-1172. [CrossRef]

11. Keihanian, F.; Saeidinia, A.; Bagheri, R.-K.; Johnston, T.-P.; Sahebkar, A. Curcumin, hemostasis, thrombosis, and coagulation. J. Cell. Physiol. 2018, 233, 4497-4511. [CrossRef] [PubMed]

12. Rukoyatkina, N.; Shpakova, V.; Bogoutdinova, A.; Kharazova, A.; Mindukshev, I.; Gambaryan, S. Curcumin by activation of adenosine A2A receptor stimulates protein kinase a and potentiates inhibitory effect of cangrelor on platelets. Biochem. Biophys. Res. Commun. 2022, 586, 20-26. [CrossRef] [PubMed]

13. Bagre, A.-P.; Jain, K.; Jain, N.-K. Alginate coated chitosan core shell nanoparticles for oral delivery of enoxaparin: In vitro and in vivo assessment. Int. J. Pharm. 2013, 456, 31-40. [CrossRef] [PubMed]

14. Tang, B.; Qian, Y.; Fang, G. Development of Lipid-Polymer Hybrid Nanoparticles for Improving Oral Absorption of Enoxaparin. Pharmaceutics 2020, 12, 607. [CrossRef] [PubMed]

15. Moon, H.T.; Jeon, O.C.; Byun, Y.; Kim, Y.J.; Lee, Y.-K. Evaluation of the oral absorption of heparin conjugated with sodium deoxycholate as a facilitating agent in GI tract. Macromol. Res. 2009, 17, 79-83. [CrossRef] 
16. Yan, Y.; Sun, Y.; Wang, P.; Zhang, R.; Huo, C.; Gao, T.; Song, C.; Xing, J.; Dong, Y. Mucoadhesive nanoparticles-based oral drug delivery systems enhance ameliorative effects of low molecular weight heparin on experimental colitis. Carbohydr. Polym. 2020, 246, 116660. [CrossRef] [PubMed]

17. Hoffart, V.; Lamprecht, A.; Maincent, P.; Lecompte, T.; Vigneron, C.; Ubrich, N. Oral bioavailability of a low molecular weight heparin using a polymeric delivery system. J. Control. Release 2006, 113, 38-42. [CrossRef]

18. Duttagupta, D.S.; Jadhav, V.M.; Kadam, V.J. Chitosan: A propitious biopolymer for drug delivery. Curr. Drug Deliv. 2015, 12, 369-381. [CrossRef]

19. Kothale, D.; Verma, U.; Dewangan, N.; Jana, P.; Jain, A.; Jain, D. Alginate as Promising Natural Polymer for Pharmaceutical, Food, and Biomedical Applications. Curr. Drug Deliv. 2020, 17, 755-775. [CrossRef]

20. Iacob, A.T.; Lupascu, F.G.; A potrosoaei, M.; Vasincu, I.M.; Tauser, R.G.; Lupascu, D.; Giusca, S.E.; Caruntu, I.-D.; Profire, L. Recent Biomedical Approaches for Chitosan Based Materials as Drug Delivery Nanocarriers. Pharmaceutics 2021, 13, 587. [CrossRef]

21. Fan, B.; Xing, Y.; Zheng, Y.; Sun, C.; Liang, G. pH-responsive thiolated chitosan nanoparticles for oral low-molecular weight heparin delivery: In vitro and in vivo evaluation. Drug Deliv. 2016, 23, 238-247. [CrossRef]

22. Yin, X.B.; Yu, Q.Z.; Li, B.W.; Zhang, C.D. Preparation and Characterization of Sodium Alginate/Chitosan Composite Nanoparticles Loaded with Chondroitin Sulfate. Adv. Mater. Sci. Eng. 2021, 2021, 6665488. [CrossRef]

23. Treenate, P.; Monvisade, P. In vitro drug release profiles of $\mathrm{pH}$-sensitive hydroxyethylacryl chitosan/sodium alginate hydrogels using paracetamol as a soluble model drug. Int. J. Biol. Macromol. 2017, 99, 71-78. [CrossRef] [PubMed]

24. Li, P.; Dai, Y.-N.; Zhang, J.-P.; Wang, A.-Q.; Wei, Q. Chitosan-alginate nanoparticles as a novel drug delivery system for nifedipine. Int. J. Biomed. Sci. 2008, 4, 221-228. [PubMed]

25. Thai, H.; Thuy Nguyen, C.; Thi Thach, L.; Thi Tran, M.; Duc Mai, H.; Thi Thu Nguyen, T.; Duc Le, G.; Van Can, M.; Dai Tran, L.; Bach, G.L.; et al. Characterization of chitosan/alginate/lovastatin nanoparticles and investigation of their toxic effects in vitro and in vivo. Sci. Rep. 2020, 10, 909. [CrossRef] [PubMed]

26. Yan, L.; Zhu, M.; Wang, D.; Tao, W.; Liu, D.; Zhang, F.; Linhardt, R.J.; Ye, X.; Chen, S. Oral Administration of Fucosylated Chondroitin Sulfate Oligomers in Gastro-Resistant Microcapsules Exhibits a Safe Antithrombotic Activity. Thromb. Haemost. 2021, 121, 15-26. [CrossRef]

27. Bhunchu, S.; Rojsitthisak, P.; Rojsitthisak, P. Effects of preparation parameters on the characteristics of chitosan-alginate nanoparticles containing curcumin diethyl disuccinate. J. Drug Deliv. Sci. Technol. 2015, 28, 64-72. [CrossRef]

28. Paluck, S.J.; Nguyen, T.H.; Maynard, H.D. Heparin-Mimicking Polymers: Synthesis and Biological Applications. Biomacromolecules 2016, 17, 3417-3440. [CrossRef]

29. Raval, N.; Maheshwari, R.; Kalyane, D.; Youngren-Ortiz, S.R.; Chougule, M.B.; Tekade, R.K. Chapter 10-Importance of Physicochemical Characterization of Nanoparticles in Pharmaceutical Product Development. In Basic Fundamentals of Drug Delivery; Tekade, R.K., Ed.; Academic Press: Cambridge, MA, USA, 2019; pp. 369-400.

30. Yuan, Y.; Zhang, S.; Ma, M.; Wang, D.; Xu, Y. Encapsulation and delivery of curcumin in cellulose nanocrystals nanoparticles using $\mathrm{pH}$-driven method. LWT 2022, 155, 112863. [CrossRef]

31. Sushko, N.; Firsov, S.; Zhbankov, R.; Tsarenkov, V.; Marchewka, M.; Ratajczak, C. Vibrational spectra of heparins. J. Appl. Spectrosc. 1994, 61, 704-707. [CrossRef]

32. Eleraky, N.E.; Swarnakar, N.K.; Mohamed, D.F.; Attia, M.A.; Pauletti, G.M. Permeation-Enhancing Nanoparticle Formulation to Enable Oral Absorption of Enoxaparin. AAPS PharmSciTech 2020, 21, 88. [CrossRef]

33. Xu, G.; Li, L.; Bao, X.; Yao, P. Curcumin, casein and soy polysaccharide ternary complex nanoparticles for enhanced dispersibility, stability and oral bioavailability of curcumin—ScienceDirect. Food Biosci. 2020, 35, 100569. [CrossRef]

34. D'Souza, A.A.; Devarajan, P.V. Bioenhanced oral curcumin nanoparticles: Role of carbohydrates. Carbohydr. Polym. 2016, 136, 1251-1258. [CrossRef] [PubMed]

35. Corcione, C.E.; Frigione, M. Characterization of Nanocomposites by Thermal Analysis. Materials 2012, 5, 2960-2980. [CrossRef]

36. de Moura, A.; Gaglieri, C.; da Silva-Filho, L.C.; Caires, F.J. Mechanochemical synthesis, characterization and thermoanalytical study of a new curcumin derivative. J. Therm. Anal. Calorim. 2021, 146, 587-594. [CrossRef]

37. Pantwalawalkar, J.; More, H.; Bhange, D.; Patil, U.; Jadhav, N. Novel curcumin ascorbic acid cocrystal for improved solubility. J. Drug Deliv. Sci. Technol. 2021, 61, 102233. [CrossRef]

38. Sadeghi, F.; Ashofteh, M.; Homayouni, A.; Abbaspour, M.; Nokhodchi, A.; Garekani, H.A. Antisolvent precipitation technique: A very promising approach to crystallize curcumin in presence of polyvinyl pyrrolidon for solubility and dissolution enhancement. Colloids Surf. B Biointerfaces 2016, 147, 258-264. [CrossRef]

39. Miao, R.; Liu, J.; Wang, J. Overview of mouse pulmonary embolism models. Drug Discov. Today Dis. Models 2010, 7, 77-82. [CrossRef]

40. Beviglia, L.; Poggi, A.; Rossi, C.; McLane, M.A.; Calabrese, R.; Scanziani, E.; Cook, J.J.; Niewiarowski, S. Mouse antithrombotic assay. Inhibition of platelet thromboembolism by disintegrins. Thromb. Res. 1993, 71, 301-315. [CrossRef]

41. Shi, J.; Wu, S. The effect of curcumin on platelet aggregation and thrombosis in rats. Acad. J. Chin. PLA Med. Sch. 1996, 1, 31-33.

42. Azevedo, M.A.; Bourbon, A.I.; Vicente, A.A.; Cerqueira, M.A. Alginate/chitosan nanoparticles for encapsulation and controlled release of vitamin B2. Int. J. Biol. Macromol. 2014, 71, 141-146. [CrossRef] [PubMed] 
43. Bernabé-Pineda, M.; Ramírez-Silva, M.T.; Romero-Romo, M.; González-Vergara, E.; Rojas-Hernández, A. Determination of acidity constants of curcumin in aqueous solution and apparent rate constant of its decomposition. Spectrochim. Acta A Mol. Biomol. Spectrosc. 2004, 60, 1091-1097. [CrossRef]

44. Gupta, A.K.; Chopra, B.S.; Vaid, B.; Sagar, A.; Raut, S.; Badmalia, M.D.; Ashish; Khatri, N.A.-O. Protective effects of gelsolin in acute pulmonary thromboembolism and thrombosis in the carotid artery of mice. PLoS ONE 2019, 14, e0215717. [CrossRef]

45. Kim, M.S.; Lee, K.A. Antithrombotic activity of methanolic extract of Umbilicaria esculenta. J. Ethnopharmacol. 2006, 105, 342-345. [CrossRef] [PubMed]

46. Choi, J.H.; Kim, S.; Kim, S.J. Spirulan from blue-green algae inhibits fibrin and blood clots: Its potent antithrombotic effects. J. Biochem. Mol. Toxicol. 2015, 29, 240-248. [CrossRef] [PubMed]

47. Deng, J.; Ren, M.; Dai, X.; Qu, D.; Yang, M.; Zhang, T.; Jiang, B. Lysimachia christinae Hance regresses preestablished cholesterol gallstone in mice. J. Ethnopharmacol. 2015, 166, 102-108. [CrossRef] [PubMed]

48. Shen, D.S.; Yang, Y.J.; Liu, X.W.; Kong, Z.; Li, J.Y. Protective effect of aspirin eugenol ester on mice with acute pulmonary embolism. Chin. J. Vet. Med. 2019, 39, 1836-1839.

49. Alexakis, T.; Boadi, D.K.; Quong, D.; Groboillot, A.; O’Neill, I.; Poncelet, D.; Neufeld, R.J. Microencapsulation of DNA within alginate microspheres and crosslinked chitosan membranes for in vivo application. Appl. Biochem. Biotechnol. 1995, 50, 93-106. [CrossRef]

50. Lopes, M.; Shrestha, N.; Correia, A.; Shahbazi, M.A.; Sarmento, B.; Hirvonen, J.; Veiga, F.; Seiça, R.; Ribeiro, A.; Santos, H.A. Dual chitosan/albumin-coated alginate/dextran sulfate nanoparticles for enhanced oral delivery of insulin. J. Control. Release Off. J. Control. Release Soc. 2016, 232, 29-41. [CrossRef]

51. Chen, G.; Chen, J.; Chen, J.; Li, R.; Jia, X.; Liu, X.; Song, B.; Zhong, S. Study on structure, anticoagulant and fibrinolytic activities of different molecular weights of heparin from Clam Coelomactra antiquata. Food Ferment. Ind. 2021, 47, 119-125.

52. Bitter, T.; Muir, H.M. A modified uronic acid carbazole reaction. Anal. Biochem. 1962, 4, 330-334. [CrossRef]

53. Dodgson, K.S.; Price, R.G. A note on the determination of the ester sulfate content of sulfated polysaccharides. Biochem. J. 1962, 84, 106-110. [CrossRef] [PubMed]

54. Gundry, S.R.; Klein, M.D.; Drongowski, R.A.; Kirsh, M.M. Clinical evaluation of a new rapid heparin assay using the dye azure A. Am. J. Surg. 1984, 148, 191-194. [CrossRef]

55. Ma, Y.; Chen, S.; Liao, W.; Zhang, L.; Liu, J.; Gao, Y. Formation, Physicochemical Stability, and Redispersibility of CurcuminLoaded Rhamnolipid Nanoparticles Using the pH-Driven Method. J. Agric. Food Chem. 2020, 68, 7103-7111. [CrossRef] [PubMed]

56. Murthy, A.; Ravi, P.R.; Kathuria, H.; Vats, R. Self-assembled lecithin-chitosan nanoparticles improve the oral bioavailability and alter the pharmacokinetics of raloxifene. Int. J. Pharm. 2020, 588, 119731. [CrossRef] [PubMed]

57. Men, Z.; Lu, X.; He, T.; Wu, M.; Su, T.; Shen, T. Microneedle patch-assisted transdermal administration of recombinant hirudin for the treatment of thrombotic diseases. Int. J. Pharm. 2022, 612, 121332. [CrossRef] 